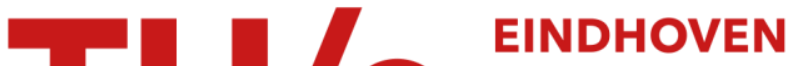 UNIVERSITY OF TECHNOLOGY
}

\section{Analog radio over fiber fronthaul for high bandwidth $5 \mathrm{G}$ millimeter-wave carrier aggregated OFDM}

\section{Citation for published version (APA):}

Konstantinou, D., Morales Vicente, A., Rommel, S., Raddo, T., Johannsen, U., \& Tafur Monroy, I. (2019). Analog radio over fiber fronthaul for high bandwidth $5 \mathrm{G}$ millimeter-wave carrier aggregated OFDM. In 21st International Conference on Transparent Optical Networks, ICTON 2019 [8840525] Institute of Electrical and Electronics Engineers. https://doi.org/10.1109/ICTON.2019.8840525

DOI:

10.1109/ICTON.2019.8840525

Document status and date:

Published: 19/09/2019

\section{Document Version:}

Accepted manuscript including changes made at the peer-review stage

\section{Please check the document version of this publication:}

- A submitted manuscript is the version of the article upon submission and before peer-review. There can be important differences between the submitted version and the official published version of record. People interested in the research are advised to contact the author for the final version of the publication, or visit the $\mathrm{DOI}$ to the publisher's website.

- The final author version and the galley proof are versions of the publication after peer review.

- The final published version features the final layout of the paper including the volume, issue and page numbers.

Link to publication

\section{General rights}

Copyright and moral rights for the publications made accessible in the public portal are retained by the authors and/or other copyright owners and it is a condition of accessing publications that users recognise and abide by the legal requirements associated with these rights.

- Users may download and print one copy of any publication from the public portal for the purpose of private study or research.

- You may not further distribute the material or use it for any profit-making activity or commercial gain

- You may freely distribute the URL identifying the publication in the public portal.

If the publication is distributed under the terms of Article 25fa of the Dutch Copyright Act, indicated by the "Taverne" license above, please follow below link for the End User Agreement:

www.tue.nl/taverne

Take down policy

If you believe that this document breaches copyright please contact us at:

openaccess@tue.nl

providing details and we will investigate your claim. 


\title{
Analog Radio Over Fiber Fronthaul for High Bandwidth 5G Millimeter-Wave Carrier Aggregated OFDM
}

\author{
Dimitrios Konstantinou*, Alvaro Morales*, Simon Rommel*, Thiago R. Raddo*, Ulf Johannsen ${ }^{\dagger}$ and $^{*}$ \\ Idelfonso Tafur Monroy* \\ *Institute for Photonic Integration, Eindhoven University of Technology, 5600 MB Eindhoven, Netherlands \\ ${ }^{\dagger}$ Centre for Wireless Technology, Eindhoven University of Technology, 5600 MB Eindhoven, Netherlands \\ e-mail:d.konstantinou@tue.nl
}

\begin{abstract}
The increasing demands for high capacity and ultra-low latency services require to introduce a $5 \mathrm{G}$ mobile communications infrastructure based on a centralized radio access network with space division multiplexed optical fronthaul using radio-over-fiber. The transmission of carrier aggregated 5G OFDM signals over an analog radioover-fiber fronthaul link is experimentally demonstrated. Multi-Gbit/s data rates are achieved in limited bandwidth, with BER below the 25 \% overhead FEC limit after millimeter-wave wireless transmission over $2.2 \mathrm{~m}$. Keywords: Radio-over-fiber, OFDM, 5G-NR, millimeter-wave communications, Ka-band wireless.
\end{abstract}

\section{INTRODUCTION}

The revolutionized infrastructure of the future $5 \mathrm{G}$ communication networks will provide massive advancements to the existing telecommunication services. These networks will offer broadband connectivity to a very large number of end users with a guaranteed quality of service (QoS) [1]. It is expected by the 5G key performance indicators (KPIs) that the capacity of 5G networks will increase by 1000 times, offering data rates varying between 0.25 to $1 \mathrm{Gbit} / \mathrm{s}$ with a peak of $10 \mathrm{Gbit} / \mathrm{s}$ to end users concentrated in hot-spot areas, e.g., malls, universities and football stadiums [2]. Very reliable networks will be constructed with low latency. That is due to the significant increase of $5 \mathrm{G}$ base stations (BS) per unit area operating in small cells. Thousands of base stations installed in cell towers, building rooftops or even on city light-poles will ensures continued connectivity of mobile connection when a user moves from one communication cell to another [3]. Therefore, the credibility of the impending wireless networks will be improved decisively.

5G will be capable of supporting groundbreaking applications such as ultra-high definition video streaming, holographic remote interaction and autonomous driving that currently cannot be established by the existing longterm evolution (LTE) networks. The key requirements for flexible 5G mobile communications in small cell deployments are low latency (<1 ms), high throughput and low power consumption [4]. In order to achieve this, new spectrum assignments in the lower millimeter wave (mm-wave) range are being considered, which together with a new radio interface and an adapted and flexible numerology for orthogonal frequency division multiplexing (OFDM) are envisioned to achieve peak user data rates in the Gbit/s range [5], [6]. Analog optical fronthaul has been suggested as the most efficient way to alleviate the large signal bandwidths required in a centralized radio access network (C-RAN) architecture [7].

Combining analog radio-over-fiber (ARoF) fronthaul with flexible carrier aggregation, signal generation and distribution-as shown in Fig. 1-allows optimum resource utilization and enables centralization of network complexity at the central office (CO). The $2^{\text {nd }}$ phase 5G-PPP project blueSPACE augments the concept of ARoF fronthaul using spatial division multiplexing (SDM) in the optical domain with multi-core fibers (MCF), which can drastically increase system capacity and enable novel techniques such as integrated optical beamforming networks [7], [8]. Photonic integration allows miniaturization of optical signal generation as well as optical to RF conversion and is foreseen within the blueSPACE project. The concept of a highly centralized RAN with a pool of potentially virtualized baseband units (BBUs) in combination with ARoF fronthaul over MCF not only offers maximum flexibility for capacity assignment, but also seamlessly enables software controlled networking (SDN) and network function virtualization (NFV)—and hence network slicing.

In this work, the transmission of carrier aggregated OFDM signals following the 5G new radio (5G NR) numerology is demonstrated over a mm-wave analog RoF link. Signals with different modulation parameters are generated and evaluated in terms of bit error rate (BER) performance after optical and wireless transmission on a $28 \mathrm{GHz}$ carrier. Multiband 5G OFDM signals are successfully transmitted with data rates of up to 4.8 Gbit/s and maximum bandwidth of $1.96 \mathrm{GHz}$. BER levels below the $25 \%$ forward error corrections (FEC) limit are measured paving the way towards the support of a larger number of users as well as of high throughput required by $5 \mathrm{G}$ fronthaul networks. The proposed experimental system is an efficient key enabler for the generation and transmission of mm-wave signals for medium-range links capable of fulfilling the increasing demands of the new era of mobile communications. 


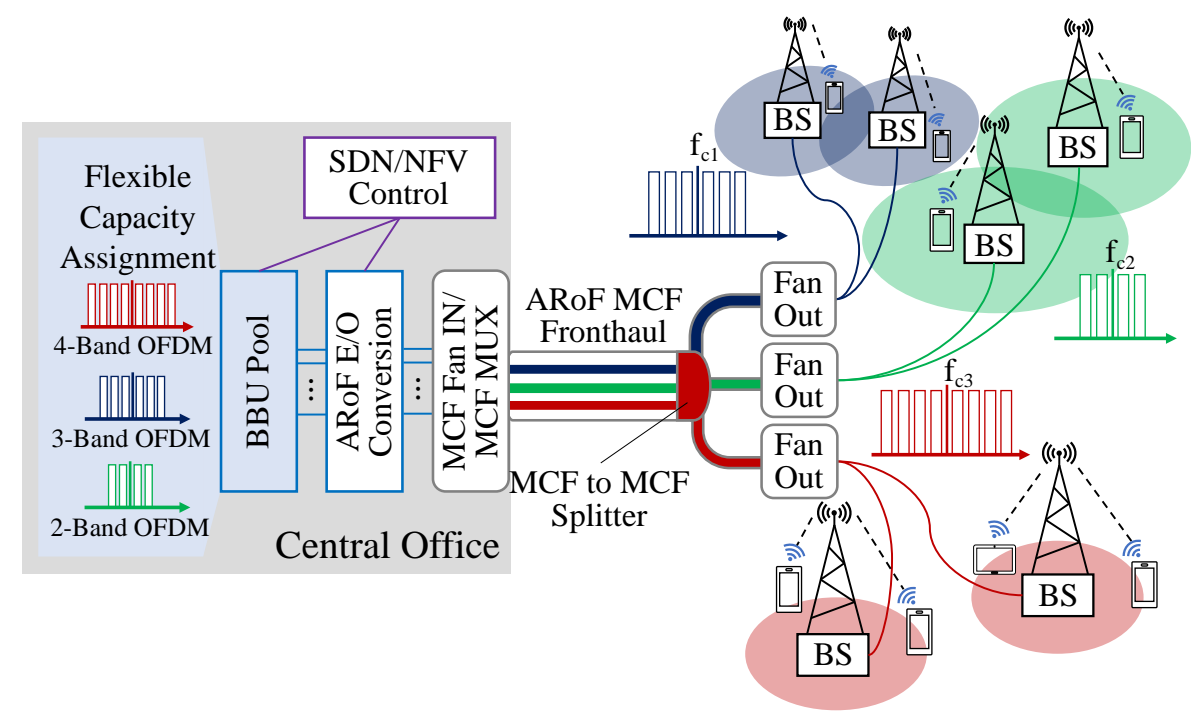

Figure 1. RAN architecture based on ARoF and the use of multi-core fiber, illustrating flexible carrier aggregation and signal distribution.

\section{ARoF Ka-BAND TRANSMISSION SETUP}

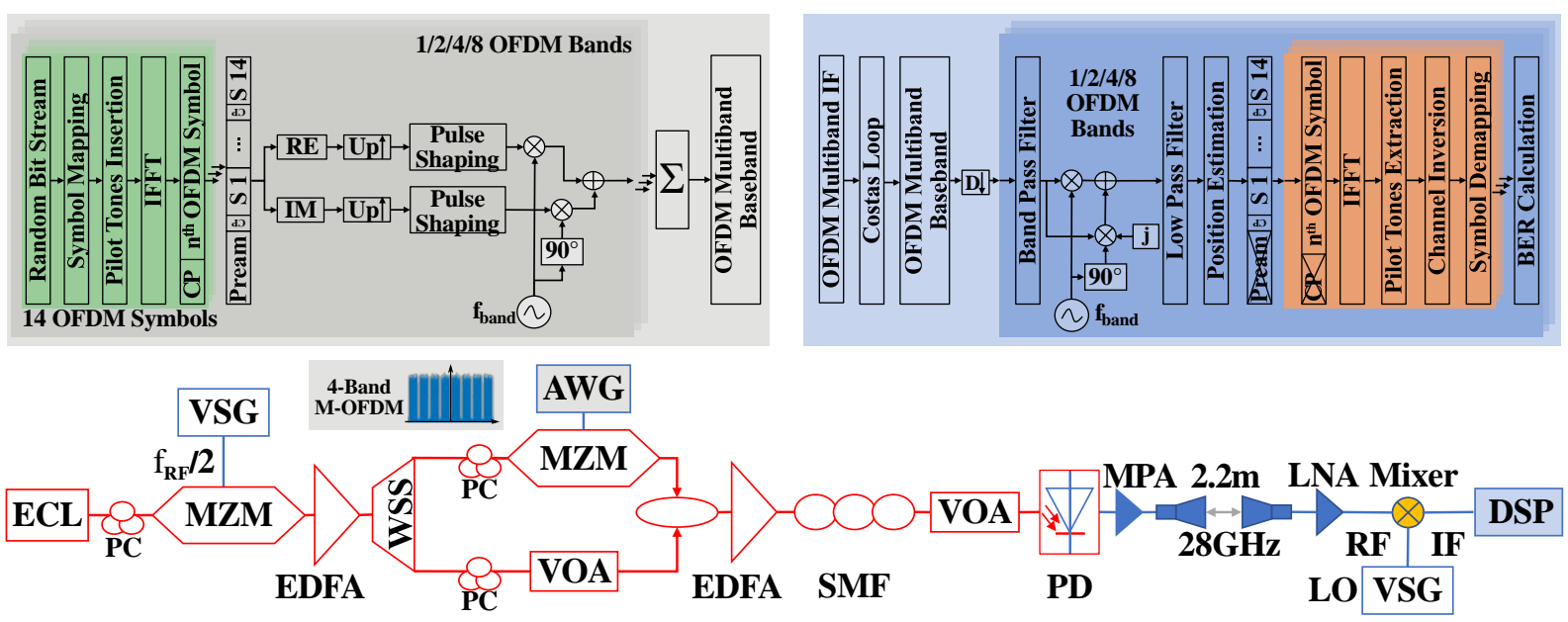

Figure 2. The schematic of the experimental setup and digital signal processing for signal generation at the transmitter and BER analysis at the receiver.

The experimental setup for ARoF transmission of multiband OFDM (M-OFDM) signals is shown in Fig. 2, including the digital signal processing both at the transmitter and receiver side. At the transmitter, the M-OFDM signal is synthesized by mapping QAM symbols generated from a random bit stream onto the OFDM subcarriers spaced at $\mathrm{f}_{\mathrm{scs}}=60 \mathrm{kHz}$. The OFDM blocksize is either 2048 or 4096-with 1650 and 3300 active subcarriers, respectively. On every $12^{\text {th }}$ subcarrier a pilot tone is inserted. After converting to the time domain using an inverse fast Fourier transform (IFFT), a cyclic prefix (CP) with a size of $6.25 \%$ of the blocksize is prepended to each OFDM symbol in order to prevent inter-symbol interference. OFDM frames are formed of 14 OFDM symbols each and attached to a preamble equal to twice the blocksize. The complex baseband signal is split into its real and imaginary components, upsampled and pulse shaped by a raised cosine filter, before being upconverted to the target band frequency using a local oscillator. The resulting signals for the different bands are summed in the time domain, generating the final M-OFDM signal. In the experiment, the modulation order of the QAM symbols $\mathrm{M}_{\mathrm{QAM}}$ is equal to 4 and 16 and the number of OFDM bands is varied between 1 and 8 .

Figure 2 also shows the block diagram of the ARoF link where two optical tones are generated by modulating the signal from an external cavity laser (ECL) with a Mach-Zehnder modulator (MZM) biased at its minimum transmission point and driven with a sinusoid at $f_{R F} / 2$ from a vector signal generator (VSG). Consequently, two tones are created with a supressed carrier and a frequency distance of $\mathrm{f}_{\mathrm{RF}}$. An erbium doped fiber amplifier (EDFA) amplifies the two tones and a wavelength selective switch (WSS) separates them. One of the tones is modulated with the M-OFDM signal in a second MZM. A variable attenuator (VOA) regulates the power of the copropagating tone (CT) which is recombined with the optical signal (OS). 
Both CT and OS are boosted by another EDFA before being launched into a span of $10 \mathrm{~km}$ standard single mode fiber (SMF). The optical spectrum at the input of the SMF as well as the signals at the output ports of the WSS are illustrated in Fig. 3. The total power at the output of the SMF is controlled by the second VOA. The RF signal is generated by the heterodyne beating between the OS and CT on a high-speed photodiode (PD) with a bandwidth of $40 \mathrm{GHz}$ [9]. The generated RF wave at a carrier frequency of $28 \mathrm{GHz}$ is amplified by a medium power amplifier (MPA) with $30 \mathrm{~dB}$ gain and transmitted over a $2.2 \mathrm{~m}$ wireless link using a pair of Ka-band standard gain horn antennas with a gain of $20 \mathrm{dBi}$ each. A low noise amplifier (LNA) boosts the signal by $15 \mathrm{~dB}$ before it is downconverted by a mixer to an intermediate frequency (IF) $f_{I F}=f_{R F}-f_{L O}$. The electrical LO is provided by a VSG at $\mathrm{f}_{\mathrm{LO}}=25.7 \mathrm{GHz}$. The received waveform is captured for offline processing by a digital sampling oscilloscope (DSO). Figure 4 shows the optical and electronic components of the experimental setup.

The receiver DSP uses a Costas loop to perform carrier and phase recovery and convert the IF signal to baseband. Next, the signal is downsampled and a bank of band pass filters isolates the bands. In each band, the preamble is used for time synchronization and discarded. From each of the 14 symbols, the CP is discarded and the FFT is performed. The received pilot tones, $\mathrm{P}_{\mathrm{Rx}}$, are compared to the transmitted ones, $\mathrm{P}_{\mathrm{TX}}$, giving the channel response $\mathrm{H}_{\mathrm{Ch}}=\mathrm{P}_{\mathrm{Rx}} / \mathrm{P}_{\mathrm{Tx}}$ which is used to reverse the impact of the channel [10]. The received symbols are demodulated for BER evaluation.

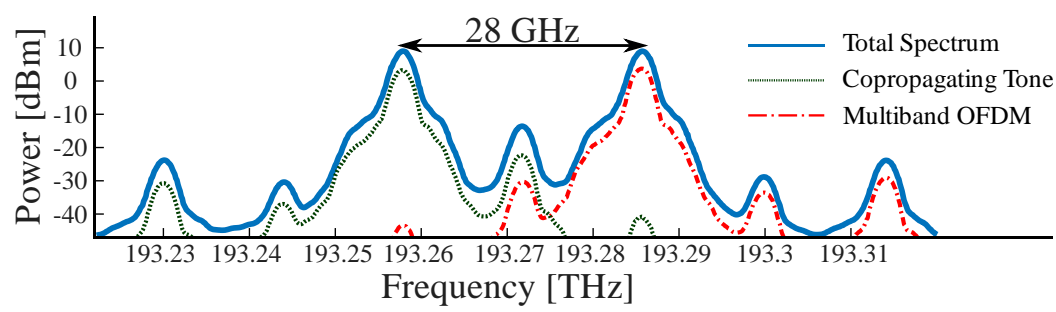

Figure 3. The optical spectrum at the input of the 10km single mode fiber (blue), the copropagating tone (green) and the optical signal (red).

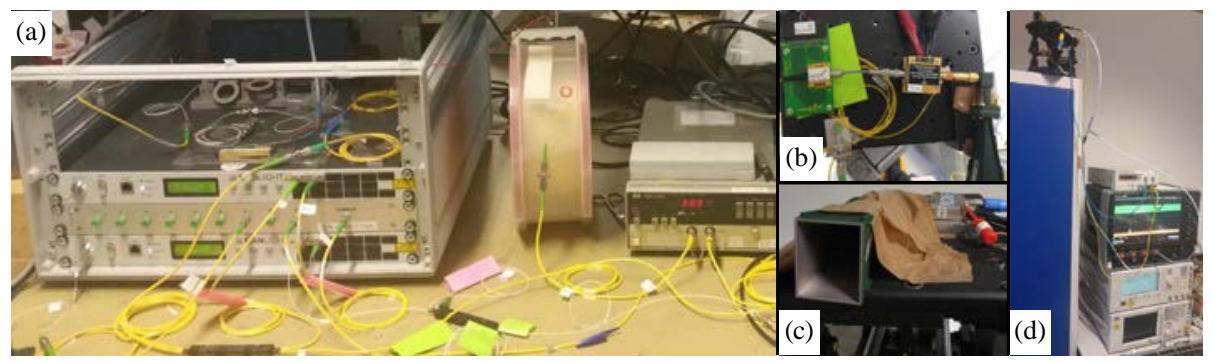

Figure 4. The experimental setup: (a) optical signal generation and fiber transmission, (b) PD and MPA connected to the transmitting antenna, (c) receiving antenna connected to the LNA, (d) the VSG and the DSO capturing the received signal traces.

\section{EXPERIMENTAL RESULTS}

The ARoF fronthaul link is evaluated by measuring the BER performance after wireless transmission of the M-OFDM signals. Figure 5 depicts two diagrams of BER with respect to optical power at the input of the PD for $\mathrm{M}_{\mathrm{QAM}}=16$ and 4 (left) or 8 (right) bands. It also shows the received constellation diagrams for all bands captured at an optical power of $3.5 \mathrm{dBm}$ for the 4-band and at $4 \mathrm{dBm}$ for the 8-band OFDM. Furthermore, Table 1 summarizes the obtained results for different signal combinations as a function of the BER limits of $3.8 \times 10^{-3}$ and $1.32 \times 10^{-2}$ corresponding to forward error correction with $7 \%$ and $25 \%$ overhead $(\mathrm{OH})$, respectively.

For configurations with few bands, lower BERs are observed, as signal power is spread over less bands and hence the received signal has a better signal to noise ratio (SNR). Similarly, as with larger blocksizes the symbol duration is reduced, the received power per symbol—and thus the SNR — is lower. Both graphs show the system to be SNR limited and thus any increase in available transmitter power will result in an improved BER performance or allowing longer transmission distances. For the evaluated signal with 4 bands in Fig. 4, a BER below the limit for $25 \%$ overhead FEC is achieved, allowing a data rate of $1.2 \mathrm{Gbit} / \mathrm{s}$ within a bandwidth of $491.5 \mathrm{MHz}$. Similarly, for the 8 band signal a bit rate of $2.4 \mathrm{Gbit} / \mathrm{s}$ is transmitted over bandwidth of less than $1 \mathrm{GHz}$ while with an increased blocksize the data rate becomes $4.8 \mathrm{Gbit} / \mathrm{s}$ with a bandwidth of $1.96 \mathrm{GHz}$.

These results are promising in terms of capacity and data rate. It is also expected that they can be improved by the optimization of the trade-off between power, bandwidth and data rate. This goal can be accomplished by providing additional transmitted power and by optimizing the system with regards to the efficiency of the RF signal generation. Consequently, OFDM signals with a greater number of bands and higher order QAM modulated symbols will be supported. 

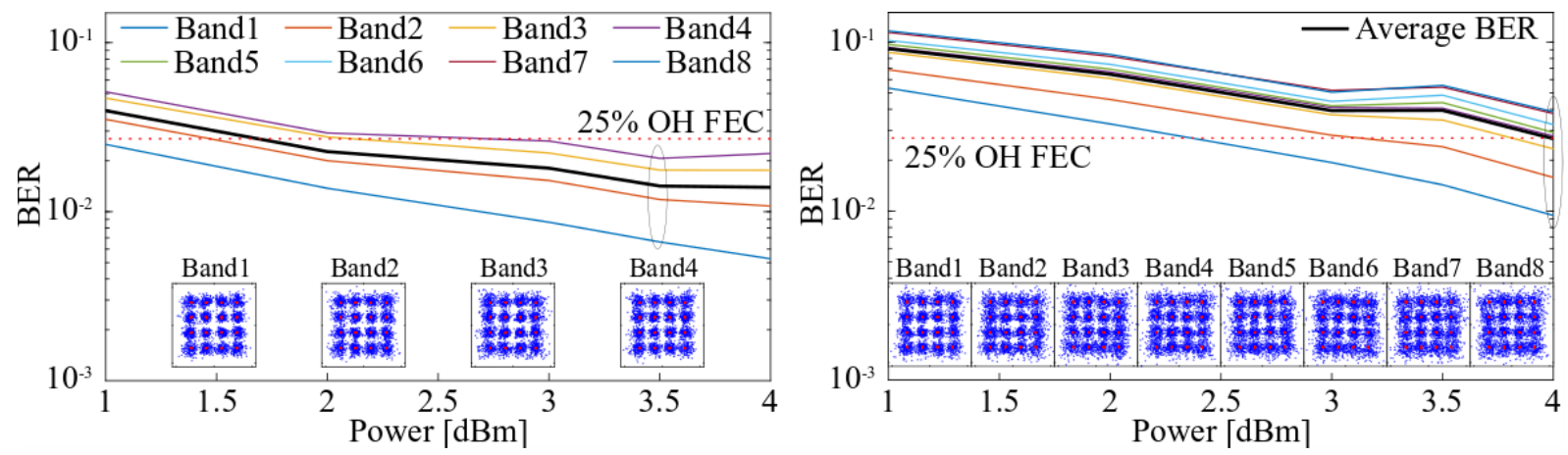

Figure 5. BER against optical power for a 4 (left) and 8 (right) band M-OFDM signal using 16 QAM symbols versus the input power at the PD; the constellation diagrams are depicted for optical powers of $3.5 \mathrm{dBm}$ and 4 $d B m$, respectively.

Table 1. Required FEC overhead for the different M-OFDM signal Configurations.

\begin{tabular}{rcccc}
\hline Block size & \multicolumn{2}{c}{2048} & \multicolumn{2}{c}{4096} \\
Mod. & 4-QAM & 16-QAM & 4-QAM & $16-Q A M$ \\
\hline Bands & $7 \%$ & $7 \%$ & $7 \%$ & $25 \%$ \\
\hline 2 & $7 \%$ & $7 \%$ & $7 \%$ & $25 \%$ \\
\hline 4 & $7 \%$ & $7 / 25 \%$ & $7 / 25 \%$ & $25 \%$ \\
\hline 8 & $7 / 25 \%$ & $25 \%$ & $7 / 25 \%$ & $25 \%$ \\
\hline
\end{tabular}

\section{CONCLUSIONS}

The transmission of carrier aggregated OFDM signals following the $5 \mathrm{G}$ numerology over a $28 \mathrm{GHz} \mathrm{ARoF}$ fronthaul link is demonstrated, finding bit error rates below the limit for a $25 \%$ overhead FEC after wireless transmission over $2.2 \mathrm{~m}$. Data rates between $1.2 \mathrm{Gbit} / \mathrm{s}$ and $4.8 \mathrm{Gbit} / \mathrm{s}$ over respective bandwidths of $491.5 \mathrm{MHz}$ and $1.96 \mathrm{GHz}$ are successfully demonstrated. The observed results showcase ARoF fronthaul as a prominent candidate for 5G, providing maximum flexibility in the fronthaul segment and achieving multi-Gbit/s performance over limited bandwidths. The system demonstrated fits the requirements for next generation mobile networks, enabling the use of mm-wave frequencies for medium-range links such as building to building communications, indoor wireless distribution or wireless access where obstacles prevent fiber deployment.

\section{ACKNOWLEDGEMENTS}

This work was partially funded by the 5G STEP FWD, blueSPACE, CELTA, and 5G-PHOS projects with funding from the European Union's Horizon 2020 research and innovation programme under grant agreement numbers 722429, 762055, 675683, and 761989, respectively.

\section{REFERENCES}

[1] L. Cominardi et al.: Understanding QoS Applicability in 5G Transport Networks, in Proc. BMSB, pp. 1-5, Jun. 2018.

[2] S. Rommel, T. R. Raddo and I. Tafur Monroy: The fronthaul infrastructure of 5G mobile networks, in Proc. IEEE CAMAD, Sep. 2018.

[3] J. F. Valenzuela-Valdés et al.: On the Ultra-Dense Small Cell Deployment for 5G Networks, in IEEE 5G World Forum (5GWF), Silicon Valley, CA, pp. 369-372, Jul. 2018.

[4] International Telecommunication Union (ITU) - Telecommunication Standardization Sector, Geneva, FG IMT-2020: Report on Standards Gap Analysis, 2016.

[5] 3GPP: Study on New Radio (NR) Access Technology - Physical Layer Aspects, Rel. 14, TR 38.802, 2017.

[6] Qualcomm Technologies: Making 5G NR a reality. Leading the technology inventions for a unified, more capable 5G air interface, San Diego, CA USA, 2016.

[7] S. Rommel et al.: High-Capacity 5G Fronthaul Networks Based on Optical Space Division Multiplexing, in IEEE Transactions on Broadcasting, Mar. 2019.

[8] blueSPACE Consortium: Space Division Multiplexing 5G Fronthaul with Analog and Digital Radio-overFiber and Optical Beamforming—the blueSPACE concept, doi:10.5281/zenodo.1402052, EU, Aug. 2018.

[9] D. Konstantinou et al.: High-Speed Wireless Access in Forested Rural Areas Using Analog Radio-overFiber Technology, in Proc. LAOP, Nov. 2018, paper Tu2B.4.

[10] L. C. P. Cavalcante et al.: Performance evaluation of wavelet-coded OFDM on a 4.9 Gb/s W-band radioover-fiber link, J. Lightwave. Technol., vol. 35, no. 14, pp. 2803-2809, Jul. 2017. 